\title{
THE IMPACT OF CULTURAL VALUES ON MARKETING OF CHINESE NATIONAL PARKS: AN EXPLORATORY RESEARCH FOR COMMUNICATION STRATEGY
}

\author{
Baifang CHENG, Catherine Sarlandie de La ROBERTIA \\ CREM UMR CNRS 6211, University Rennes 1, CREC ESCC, France
}

\begin{abstract}
The aim of this study is to draw out the principle values of chinese tourists to national parks in china so as to improve the parks communication strategy to consumers. The literature clearly provides support and empirical evidence linking both culture and consumption. Cultural values have been shown to be efficient, measurable sets of variable that are fewer, more centrally held and more closely relating to consumer behaviour than demographic and psychographic measures.
\end{abstract}

The data were obtained from a questionnaire on chinese cultural values, which was distributed to a sample of 133 visitors to national park potatso. After a descriptive analysis and a factor analysis, we propose some values that can be used in communication strategy to increase the number of visits to chinese national parks

\section{INTRODUCTION}

Ever since the opening of China, the growth of annual economy is always higher than $8 \%$. The quality of life is increasing, more and more Chinese people are leaving for vacation. Tourism is seen as an agent of change from economic, cultural, environmental and social perspectives, and so is utilized in general as an economic engine, boosting the living standards of destination. Confronting with crisis, this industry is set to become more important. China has done many efforts to stimulate consumption - since March 2009, much of Chinese provinces launched their new tourist policy for drawing national tourists to visit their place. 2009 has been named as 'ecotourism year'.

For long time, work is a major part of daily routine but in a modern society, leisure becomes to supplant work as a significant part of an individual's life. In 2008, the domestic travelling population reached 1.6 billion and the domestic travelling income amounted to 777.1billion Yuan (97.1 billion US dollars). More and more tourists are apt to look for authentic, distinctive themes supplemented by a high quality of service along with socially-responsible practice. The experienced traveller indeed epitomizes a special niche sector setting new product trends and encouraging business to design a series of commodities that could prospectively enrich tourist experience. Unlike common offerings prevalent to the mass tourism market, unique leisure initiatives tied to cultural, ecological themes have gradually gained in popularity 
for those individuals longing for the enrichment of quality of life. These experienced consumers seek educational, psychological and spiritual benefits while travelling.

A national park is firstly a great space associating vocation with protection. Starting from the NorthAmerican, the national parks multiplied in the world, the policies of protection and conservation of the landscapes, flora, fauna and water levels, were therefore made compatible with tourism strategies. The concept of national park does exist in different large countries: Canada, Australia, and in Europe too. The same applies to Africa, mainly by the wish of protecting the large fauna which is there considered as exceptional. There are over 9,800 existing national parks worldwide with the Yellowstone National Park in the US being the first one to be established in 1872 .

In China, there are 187 "picturesque and famous national sites" managed by the ministry for construction. There is no legal definition of national park in China but some provinces try to introduce the American national park system. The first "picturesque and famous national site" was created in 1982 and the first national park, Potatso, was created in 2006 in Shangri-La, located in the southwest of Yunnan province. "By establishing the Potatso national park, China has taken the first step towards blending tourism development with natural protection," said Song Yinxiu, head of the park's administrative bureau. Before the creation of this first national park, these "picturesque and famous national sites" were generally considered as Chinese national parks. In most cases State Department and local government are sharing the park management. In majority of the Chinese national parks, the priority is given to productivity, which results in the qualitative degradation of sites. Mass tourism increasingly carries negative influences. A new national park system will be a good solution because it tied leisure with cultural, ecological themes. How to balance this relation between supply and of national park in China? Which are anticipations of the Chinese tourist with respect to the national park? What suitable communication strategy can we propose to national park?

The aim of this study is to find out Chinese visitors' of national parks basic values. The literature clearly provides support and empirical evidence linking culture and consumption. Cultural values have been shown to be efficient, measurable sets of variables that are less numerous, more centrally held and more closely related to consumer behaviour than demographic and psychographic measures. Our data were firstly obtained from 9 interviews of visitors of national parks in China and 30 pre-questionnaires. After combining the values obtained in our past research (Sarlandie de La Robertie \& Cheng 2007: 94), with the cultural values founded in the questionnaire, a quantitative research of 200 questionnaires is based on the outputs of this preliminary qualitative research and the reviews of related literature. Finally, we propose values that can be used by parks managers (in China or outward China) who want to improve their communication strategy toward Chinese tourists.

\section{LITERATURE REVIEW}

Chinese consumption is varied because the consumers are now confronted with the products of the whole world. Moreover, the fast growth generates a social stratification and a dynamic mobilization in China (Walder, 1989: 418; Bian, 2002:114). There are no official social classes, but much of Chinese researchers define the consumers by income, profession and other diverse criteria. In spite of stratification, there is not yet in China a middle class like in the industrialized countries'. The Chinese middle class has not a stable income, neither a clear identity nor a distinct system of values. People who are in this class miss also any political motivations which ensure the development of a civil society. In other words, to better know the Chinese consumers in such a fast development, it is necessary to find out other stable and radical factors. We cannot use only traditional factors like socialprofessional or demographic variables. These variables enable us to know which the consumers are but they do not help us to find reasons which make that the Chinese consumers react differently.

The consumer does not react separately, spontaneously. He lives in a social, political and cultural context. The values are the reflection and the expression of the culture. Hofstede (1991:45) defines the values as factors that form the core of a culture -- its major demonstrations. A value is the tendency to prefer a certain state of the things to another. The values resulting from a culture are stable and durable variables to understand and predict the behaviour of the consumer. The culture and the whole of the process of socialization make it possible to the individual to build reference marks and to structure his values. Thus values and culture are indissociable. The principal interest of studying values lies in their aptitude to relay the impact of the culture on consumption, and more generally on the behavioural dynamics of the individual. So, it is necessary to emphasize subjacent personal values and their bond with expectations of the consumer; in order to adapt the communication.

The term of "culture", even if it is largely used in the 
literature found in the field of international marketing and consumer behaviour, is generally defined very vaguely (Hofstede, 1984: 391; Jeannet, Hennessey, 1988: 64; Keegan, 1989: 81; McCracken, 1988: 51; Rohnert, 1984: 116). In general, this term refers to one or more of the following elements:

- significances, attitudes, values and beliefs shared by a group of people;

- modes of reaction to the stimuli and other forms of behaviours common to a group of people;

- symbols and rites used to express significances, values divided and which guide the behaviours and the reaction to the stimuli;

- the way in which those mental constructions and those shared behaviours, like the religion, the family, the education acts.

The culture thus represents "a whole of knowledge, beliefs, standards, values, traditions ... acquired by the man as a member of such society" (Hofstede, 1980: 64). It is "collective mental programming" which will result in visible demonstrations, in particular by behaviours, habits, and the ritual. The cultural elements are shared by the majority of one society members; they are learned, because these elements are transmitted to the individuals by the means of many institutions (family, school, laws, media...); they are evolutionary, under the pressure of individual innovations and external contributions.

In marketing, the culture is always an environmental factor. The culture is integrated in all the aspects human being: himself and his personality. The links between culture and consumer behaviour are tight, because to consume is a cultural act. In a recent research, Donnel, Michael and Itamar (2000: 174) show that the culture influences the cognitive process of the consumer when it makes his decision. The culture strongly influences the practices of consumption (criteria selection, marks or products bought...). If the culture of an individual is considered, we can partly understand, explain and envisage his behaviours of consumption. However, the impact of the culture on consumption is not direct. Just as it is difficult to establish a bond between personality and behaviours of consumption, the bond between culture and consumption "is meditative". In other words, the culture acts on "intermediate variables" like: the distribution of the roles of consumption within the family, or, the process of evaluation of the products. The consumer goods convey an attachment with cultural values. They are the bridge by which the individual maintains a link with the cultural environment. This acquisition makes it possible to the individual to be socially by expressing the specific cultural impact of which he profited and the values to which he adheres. On the other hand, the culture cannot be separate with the individuals. It is not a system of abstract values which exists independently of the individuals. The culture is a whole of elements complex, implicit or explicit, bound, learned, transmitted and unconscious of which the values form a part. A value is "a durable belief that a specific mode of behaviour or goal of the existence is personally or socially preferable with another mode of behaviour or goal of the existence opposite or convergent" (Rokeach, 1973: 156). Moreover, the values are organized in "system in a continuum of relative importance". A value does not exist on its own, but rather within a hierarchical system of values. In this system, the values are classified according to their strength; there are always some values more important than others. The cultural values reflect the essential characteristics of the culture (Hofstede, 2001: 142) and constitute some of its fundamental part (Ballinger, Hofstede, 1987: 120). The culture has various functions. It exerts a pragmatic function (provides scripts to guide the behaviour), of adaptation to the environment, identity, and synchronization of the behaviours (Usunier, 2000: 137). The values, in particular, structure the beliefs, the attitudes and orientate the mode of individual behaviour, providing them a whole of solutions to the encountered problems (Terpstra, David, 1985: 83; Rice, 1993: 75; Hofstede, 2001: 158). More general than the motivations, the values are more stable and more structuring than attitudes because they are less laid out to evolve. However the values must be distinguished from the sociocultural standards. These last are very prescriptive. They determine a general framework of operation which makes it possible to the individuals to live together within the same society.

The two principal characteristics of the cultural values are their stability in time and their adaptation. Stability in time supposes that the current cultural values of a society are strongly dependent on its traditional values. At the same time, it is rare that a culture is not sustained to any foreign influence and does not adapt it. To understand the current Chinese culture and values, it proves however essential to study the traditional Chinese culture. According to Sarlandie de La Robertie (2006b), the traditional Chinese culture is still impregnating the current Chinese culture. This cultural system is not only traditional but also contemporary, and is also turned towards the future, because it is the union of the tradition and reality. It will thus influence the future of the Chinese culture. For this reason, we lay the stress in this research on the traditional culture. Another major characteristic of the cultural values is 
to influence the human behaviours (Tybout, Artz, 1884). The Chinese consumers have cultural characteristics which are very different from those of the Western consumers (Sarlandie de La Robertie, 2004). Five decades ago, Kluckhohn and Strodtbeck (1961: 112) developed their values orientation theory (structure K\&S). This structure was subsequently used by Yau (1988: 50, 1994: 62, and 2002: 258) to study Chinese cultural values in the context of marketing. Moreover, Bond and his Hong Kong colleagues have developed a trans-cultural research programme based on Hofstede's method. In the 80s, Yang (1986: 89) looked further into the profile of Taiwanese values in the context of modernization, and drew up a list of the changes recorded in the value system.

In 1994, Yau (1994: 207-209) proposed a model of the Chinese consumer's satisfaction/dissatisfaction, in which values are the important and independent variables which affect expectations relating to the product, satisfaction, and the intention of purchase. It is a typology of 12 values, which are gathered in 5 dimensions: "man and nature", "introspection", "relationship", "time", and "personal activity". The "man and nature" dimension includes values relating to the harmony with nature. The Chinese think that the man is a part of nature. Man must neither exceed it, nor control it. Man can only adapt to nature in order to reach a harmonious state. In this dimension, there is also a value which is called Yuan (fatality, ?), which affirms the relation predestined between the man and the other things. This value generates the fact that people must rely on themselves and cease complaining in difficult circumstances, because all is envisaged. Individual internal dimension includes the values of the humility, in which modesty is essential. It is necessary to avoid saying not to the others and to be flexible because one must act according to the current circumstance. Relational dimension shows the values like the respect of the authority, the dependence, the face and the orientation of the group. Yang (1986: 46) defines the social orientation as "a predisposition towards models of behaviour like social conformity, the use of non offensive strategies, the tender with social waiting, and the value granted to the external opinions, with the aim of achieve one or more goals. These objectives can be obtaining rewards, the maintenance of the harmony, the control of the feelings, the will to save the face, social acceptance. It can be a question of avoiding punishments, the embarrassment, the conflicts, the rejection, the ridiculous one, and reprisals in a social condition. Basically, that represents the tendency of a person to act as agreement with external waiting or the social standards, rather than according to the interior wishes or of the personal integrity, so that it is capable to protect his 'me public' and his social functions, as an integral part of the social network. The "time" dimension shows that the Chinese attach a strong importance to the tradition. They are proud of their long history. Continuity is very important for them. In the "personal activity" dimension, one seeks a harmony with the others. One avoids the conflict and seeks an external harmony like internal one too. In the field of human relations and especially in the family circle, Chinese people continue to attach importance to the concept of Zhong-Yong ("Constant Mean"巾庸), whose purpose is to maintain balance and harmony, directing the mind to a state of constant equilibrium. Such are dominant values which express cultural bases that we can find in the Chinese society (Sarlandie de La Robertie, 2006a).

Yau proposed a questionnaire which contains 45 proverbs to describe these five dimensions of the Chinese cultural values. These values are used in our earliest research in order to explain Chinese consumer behaviour because of this culture specificity. We added the harmony (和谐Hexie), which is a central concept in the Chinese culture -- the harmony between man and nature, the social harmony.

Some other Chinese researchers, Zhang (2003: 38, 2005: 56) and Liu (2006: 50) proved the relationship between Chinese consumer values and Chinese traditional culture, too. Liu (2005: 157) combined Yau's typology of 12 values (organized into five dimensions) and Hofstede's researches, he provided a typology of 30 values, organized into 7 dimensions.

\section{METHODOLOGY}

Both qualitative and quantitative methods were used in our research to find out Chinese tourists' cultural values. At the first stage of the research, face-to-face interviews with 9 Chinese visitors (aged from 20 to 57) of national parks were used in order to understand why and how they have chosen their visit at national parks. After combining important expressions of these interviews, the reviews of related literature and our prior research, a small-scale questionnaire survey is carried out with the initial questionnaire, aiming to test whether the questionnaire is suitable for further research. Then data have been collected through a questionnaires survey in the national park Potatso between 21 st July and 4th August 2008. The sampling frame consists of randomly selected 200 persons. As a result, the effective sample size of the study is 133 . All questionnaires are in Chinese. There are two parts in final questionnaire: the first part proposes 85 items about Chinese traditional culture. Likert's five-point 
scale is used in the first part. The second part is about the tourist behaviour in national parks. Another 9 questions about demographic characteristics of respondents are added.

The 9 interviews were volunteers and agreed to spend 45 minutes or one hour being interviewed individually. The interviews were conducted in Chinese, their mother tongue. There were two parts in the interview schedule. First part tried to understand why he/she visited a national park. In the second part, they discussed how Chinese traditional values influence them. To conclude, a third part was set apart for answers to the two principal questions: 1) what do you think about a national park? 2) What do you expect from a national park? Everyone wants to have a rupture from daily routine. They agreed that the traditional values play an important part in their life. They can feel the harmony between human and nature in national parks and famous landscapes.

The resultant data derived from the qualitative work enabled the study to set up a scale of traditional values into the survey questionnaire. We selected 80 daily expressions; a lot of expressions were proved by scholars Yau, Zhang and Liu in their researches, and we added some terms about tourist activities. A fivepoint Likert-type scale, with 1 referring to "complete agreement", and 5 to "complete disagreement", was used for measurement.

To strengthen the content validity, tourism professors, tour operators were asked to review the questionnaire to see if there was any ambiguity and mistake shown in draft questionnaire. After the content validity was secured, a pilot test of 30 subjects was conducted to ensure the clarity of wording again and to statistically test reliability of measurement using a Cronbach alpha test $(=0.824)$. The study found that the initiate scale had an acceptable reliability score.

The questionnaire for the survey was written in Chinese. It was translated into English for the data analysis and interpretation. The national park Potatso agreed to join the study. In this regard, the study population was individual tourists. A series of on-site surveys was conducted by 15 students from the faculty of ecotourism, Southwest Forestry University. The participants were selected when they were waiting tourist coach or taking a rest. It should be underlined that visitors have little time for rest, 67 questionnaires were not able to complete in time. In total, the sample of 133 visitors was deemed as useful and further analyzed. As for the data analyses, after descriptive analyses, we used factor analysis to reduce attributes to fewer dimensions. The descriptive analyses aimed to address the first research objective proposed by the study. The factor analysis was used to find key traditional values.

\section{FINDINGS AND DISCUSSION Experimentation And Findings}

The descriptive statistics of the respondents were conducted using the frequency tests and the demographics were illustrated (table 1). These visitors travel at least once a year, and more than $17 \%$ take a trip more than three times a year. Moreover, 30\% travellers have visited outside China.

The test of Cronbach's Alpha on the values scale is conducted and finds an acceptable $(=0.918)$ score. The finding outlines a reliable scale of measurement in regard to traditional values. Its internal validity, tested by Pearson's correlation, shows no item above the 0.01 level. The $p$ of Jöreskog is over 0.75 . Likewise, T-test for all items shows no item above 5, which means an alpha level of 0.01 . Our scale of Chinese traditional values is thus both reliable and valid. We did an exploratory factor analysis and we got the $\mathrm{KMO}$ of 0.805 . The result of Bartlett test of sphericity is in table 2 .

Table 2: Indice kmo and bartlett test

\begin{tabular}{|l|l|r|}
\hline Kaiser-Meyer-Olkin. &, 805 \\
\hline Bartlett test of sphericity & Chi-square test & 2403,124 \\
\cline { 2 - 3 } & ddl & 946 \\
\cline { 2 - 3 } & Significance of Bartlett &, 000 \\
\hline
\end{tabular}

These two indices showed our data can be used a factor analysis.

Finally the principal component analysis (with the rotation method Varimax) produced 12 factors, accounting for $76 \%$ of the variances. The first 6 factors are presented in table 3 .

There other factors were: group orientation, selfcontrol, independence and autonomy, respect for experience, and health. We found three factors which tied with 'harmony'. The Chinese value "harmony", can be internal (a mix of physical health and psychological balance) as well as external (relations with others, with objects and nature). $82 \%$ of visitors thought human must respect the nature. More than $90 \%$ visitors will take part in environmental protection despite it causes sometimes inconvenience to them. $91 \%$ visitors found the harmony between human and the nature in national park where they enjoyed a physical and spiral experience. There is a very strong 'man-nature' orientation as well as a positive attitude 
Table 1: Demographics of the sample $(n=133)$

\begin{tabular}{|c|c|c|c|}
\hline & Descriptive & Frequency & Percentage \\
\hline \multirow[t]{2}{*}{ Gender } & Male & 66 & $49.6 \%$ \\
\hline & Female & 67 & $50.4 \%$ \\
\hline \multirow[t]{5}{*}{ Age } & $16-24$ & 51 & $38.3 \%$ \\
\hline & $25-34$ & 41 & $30.8 \%$ \\
\hline & $35-44$ & 29 & $21.8 \%$ \\
\hline & $45-54$ & 9 & $6.8 \%$ \\
\hline & 55 or above & 3 & $2.3 \%$ \\
\hline \multirow[t]{4}{*}{ Education } & Primary or below & 0 & $0 \%$ \\
\hline & Secondary & 36 & $27 . \% 1$ \\
\hline & Graduate & 79 & $59.4 \%$ \\
\hline & Post-graduated or above & 18 & $13.5 \%$ \\
\hline \multirow[t]{10}{*}{ Occupation } & Student & 44 & $33.1 \%$ \\
\hline & Retirement & 2 & $1.5 \%$ \\
\hline & Professionals & 10 & $7.5 \%$ \\
\hline & Professor, researcher & 34 & $25.6 \%$ \\
\hline & Senior management & 10 & $7.5 \%$ \\
\hline & Middle management & 8 & $6.0 \%$ \\
\hline & Public service & 5 & $3.8 \%$ \\
\hline & SME Manager & 1 & $0.8 \%$ \\
\hline & Works & 7 & $5.3 \%$ \\
\hline & Others & 12 & $9.0 \%$ \\
\hline \multirow[t]{7}{*}{ Income } & 1000 Yuan or below & 10 & $7.5 \%$ \\
\hline & 1001-1500 Yuan & 14 & $10.5 \%$ \\
\hline & 1501-2000 Yuan & 16 & $12.0 \%$ \\
\hline & 2001-3000 Yuan & 15 & $11.3 \%$ \\
\hline & 3001-4000 Yuan & 16 & $12.0 \%$ \\
\hline & 4001-5000 Yuan & 17 & $12.8 \%$ \\
\hline & 5001 Yuan or above & 45 & $33.8 \%$ \\
\hline
\end{tabular}

towards ecology. There are also $91 \%$ visitors dreamed a simple life.

The Chinese seek independence and autonomy within the bounds of their in-group's orientations. The family is always at the centre of Chinese society. A good relationship is emphasized mainly as a source of potential support and help. Families and friends often decide what is to be done and are regarded as essential resources to succeed in life. The visitors aged upon 35 prefer travelling with family and the visitors aged from 16 to 34 like a travel with their friends. On the other hand, the importance the Chinese attach to selfcontrol increases correspondingly. In short, the Chinese visitors needs a national park to fully relax, enjoy good moments with family and friends, find harmony with nature, and gain specific knowledge about it.

\section{Discussion}

There is not yet any research which uses the Chinese traditional values in order to figure out tourists' behaviour. Our scale is reliable and valid in this research. But some items were not significant (for example item 13 and item 15). We must pay attention for those items in our future study because we have another group of data - 454 questionnaires realized outside the national park.

The on-site survey in this study was done in the national park Potatso, where the ticket price is 260 Yuan (33 US dollars). Few famous sites keep so expensive ticket. Maybe it is the reason why we found that the visitors' average income is quite high: $67.6 \%$ of them have more than 2000 Yuan (313 US dollars) a month while the average income of Chinese is only 
Table 3: Factor analysis of chinese culture values

\begin{tabular}{|c|c|}
\hline $\mathrm{N}^{\circ}$ & Factors \\
\hline & Factor 1: Harmony with people and importance of the family. (Variance $\%=11.14 \%$ ) \\
\hline 34 & We should keep harmonious with others. \\
\hline 35 & A man depends on his friends when he is not at home. \\
\hline 65 & A family will be prosperous if it is in harmony. \\
\hline 6 & It is my parents' guide that leads me to a right career choice of my life. \\
\hline 75 & I am used to listen to my parents' instruction. \\
\hline 3 & Words of my parents are important to me. \\
\hline 4 & I respect my teachers just as I respect my parents. \\
\hline 49 & I always pay attention to my teachers' edification. \\
\hline \multirow[t]{2}{*}{73} & When I make an important decision, what I consider first is my family's interest. \\
\hline & Factor 2: Situational dependences. (Variance $\%=7.73 \%$ ) \\
\hline 78 & The consuming behaviour should match with the consumer's social identity. \\
\hline 37 & One's apparel should match his/her identity. \\
\hline 30 & One's behaviour should match his/her social status. \\
\hline \multirow[t]{2}{*}{25} & Whether to express one's opinion should depend on the situation. \\
\hline & Factor 3: Group orientation. (Variance $\%=5.88 \%$ ) \\
\hline 39 & The ability to cooperate with others is more important than the individual ability. \\
\hline 76 & The feeling of involving in some organization is very important for me. \\
\hline \multirow[t]{2}{*}{29} & Sometimes we have to sacrifice our individual interest for human beings' interest. \\
\hline & Factor 4: Harmonious life with nature. (Variance $\%=5.72 \%$ ) \\
\hline 1 & For humanity's happiness, the humanity should obey the nature. \\
\hline 17 & National park and scenery scenic spot area can let me feel the harmony between human and nature. \\
\hline 11 & I love the nature. \\
\hline 68 & For avoiding natural calamity, human must conquer the nature. \\
\hline 83 & I do not like environmental protection because it causes inconvenience to me. \\
\hline \multirow[t]{2}{*}{33} & I hope that I can live in a beautiful place. \\
\hline & Factor 5: Universal harmony (Variance $\%=4.80 \%$ ) \\
\hline 21 & I like the tranquil life. \\
\hline 26 & I prefer a simple life to a material well-being life. \\
\hline 24 & I do not like complicated things. \\
\hline \multirow[t]{2}{*}{79} & Let nature take its course \\
\hline & Factor 6: Yuan (fatality). (Variance $\%=4.51 \%$ ) \\
\hline 19 & I am the only one who can be responsible for my behaviour. \\
\hline 18 & Life is fated. \\
\hline 64 & Do good work for people and animal, you will have a good retribution. \\
\hline 41 & I believe that the spirit is immortal. \\
\hline 63 & I hope I can realize a better life in the world to come. \\
\hline
\end{tabular}

1500 Yuan a month. Moreover, 73\% visitors held a university degree. We need a larger sample for testing our questionnaire. In our survey, few aged people were concerned, however more and more aged people travelling nowadays.

Like any method, the factor analysis is not free from inherent limits. Its implementation suffers in particular from the ponderous and sometimes artificial character.
It is necessary to deal with a significant number of subjects for the factors derived from analysis with more objective socio-demographic criteria. With other 454 questionnaires, a regression analysis will be done in our future study. 


\section{CONCLUSION}

The Chinese government defines a national picturesque site as a space to be admired by the people for its natural, cultural and scientific assets. On such a site, landscape, fauna, florae blend harmoniously with culture. All natural resources on it are strictly protected by the state. In their communication strategy, the national parks can firstly underline 'a place for harmony, natural and social', because in Chinese culture man is part of nature. Human activities thus enjoy pride of place in Chinese national parks - a major difference from other countries. In addition, park management can emphasize this or that value according to its principal feature. For instance, Park Potatso management can highlight a pure natural landscape where the fauna and florae are scare and where ethnic minorities such as the Tibetans are still living from generation to generation. The beauty of nature and the specific culture of one ethnic group will enrich the visitor's knowledge, which is so acquired by the high-educated and experienced national park tourist. A national park is also used to show an ecological harmony. For a national park known by mountain sites, achievement, wisdom, friendship and positive feelings all figure prominently among the values referred to. For the historic sites, deferential regard for experience, reflectiveness and intelligence are of primary importance. Furthermore, increasingly environment-conscious tourists do not only seek a break with everyday life. They expect the national park they visiting to minimize degradation of natural resources, as well as to maximize services based on their values. Combining environmental concerns, heritage conservation, scientific and tourist development, park activity becomes multipurpose, hence complex, and creates a requirement for professionalized personnel. In marketing strategies, plural values must now be factored in: nature and health, harmony, thirst for new experience and knowledge.

From the values highlighted in this research, it is so possible to derive conclusions that are policy-relevant for managers anxious to improve the attractiveness of national parks and communication with their visitors and in brief, to refashion the public image of Chinese national parks and change the terms of 'dialogue' with the tourists. Also, we can observe that these conclusions apply too to the communication strategy that "foreign" national parks - i.e. outside China - would need to set up in order to attract tourists from China.

\section{REFERENCES}

Ballinger, D. and Hofstede, G. (1987), Les Différences Culturelles dans le Management, Les Editions d'Organisation, Paris.

Bian, Y. (2002), Chinese social stratification and social mobility, Annual Reviews Social, 28, pp91-116.

Chieh-Lu, L., and Poh C.L., Garry E.C., Harry C.Z. and Alan R.G.(2007), Cross-cultural Models of Customer Service : A Case of Country Park Recreation in Hong Kong, Journal of Park and Recreation Administration, 25(3), pp 41-66.

Dong, J.S. and Chen T.(2006), 基于文化价值观的消费者行为研究, Jourrnal of Liaoning Institute of Technology, 8(5), pp18-21.

Donnel, A.B., Michael, W.M. and Itamar, S. (2000), Reasons as carries of culture: Dynamic versus dispositional models of cultural influence on decision making, Journal of Consumer Research, 27, pp157178.

Hofstede, G. (1980), Culture's Consequences: International Differences in Work-Related Values, Sage Publications, Thousand Oaks, CA.

Hofstede, G. (1984), The Cultural Relativity of the Quality of Life Concept, Academy of Management, the Academy of Management Review, Jul, p.389-398.

Hofstede, G. (1991), Cultures and Organizations: Software of the Mind, McGraw-Hill International, London.

Hofstede, G. (2001), Culture's Consequences: Comparing Values, Behaviors, Institutions Across Nations, Sage Publications, Thousand Oaks, CA.

Jeannet, J.P., and Hennessey H.D. (1988), International marketing management, MA: Houghton Mifflin, Boston.

Keegan, W.J. (1989), Global marketing management, Prentice Hall, Englewood Cliffs, NJ.

Kluckhohn, F.R. and Strodtbeck F.L. (1961), Variations in Value Orientation, Evanston, IL: Row, Peterson \& Co.

Liu, S.X. (2005), 中国消费区域差异特征分析, Sanlian Publications, Shanghai, China.

Liu, S.X.(2006), 从文化价值的角度看消费形态, Economic Management, 7, pp49-52.

McCracken, G. (1988), Culture and Consumption, Indiana University Press, Bloomington.

Oliver, R. L., Rust R. T., Varki S. (1997) Customer

Delight: Foundations, findings, and managerial insight, 
Journal of Retailing, 73(3), pp311-336.

Rice, C. (1993), Consumer Behavior: Behavioral Aspects of Marketing, Butterworth Heinemann, Oxford;

Rohnert, P.R. (1984), Toward a Conception of Culture in Cross-Cultural Psychology, Journal of Cross-Cultural Psychology, 15, pp.111-138.

Rokeach, M.J. (1973), The Nature of Human Values, Free Press, New York.

Sarlandie de La Robertie, C. (2004), Intercultural Aspects: Chinese Consumer Behavior (in Russian). Politics and Business in the Changing World, Fourth International Conference Proceedings. Obninsk, Russia, pp. 63-68.

Sarlandie de La Robertie, C. (2006a), Gestão nos países sob influência de Confucio: Implicações culturais, Global Economics and Management Review, Lisboa, vol.11, N³, pp.51-69.

Sarlandie de La Robertie, C. (2006b), China: About the Bond Between Management and Cultural Patterns - System of Values' Influence on Managerial Practice (in Russian). Politics and Business in the Changing World, Fifth International Conference Proceedings, Obninsk, Russia, pp. 231-239.

Sarlandie de La Robertie, C. and Cheng, B.F. (2007), Values in the Marketing of National Parks in China: an Exploratory Application of Means-End Chain Theory, Euro Asia Journal of Management, 17(1), pp79-102.

Terpstra, V., and David, K. (1985), The Cultural Environment of International Business, South-Western, Cincinnati.

Tybout, A.M., and Artz, N. (1994), Consumer Psychology, Annual Review of Psychology, 3, pp.131169.

Usunier, J.C. (2000), Marketing Across Culture, $3^{\text {rd }}$ edition, Financial Times/prentice Hall, London.

Walder, A.G.(1989), China Social Change in Postrevolution China, Annual Review of Sociology, 15, pp405-424.

Yang, K.S. (1986), Chinese Personality and its Change. In Bond, M.H. (ed.) The Psychology of the Chinese People, Oxford University Press, New York

Yau, O H.M. (1988), Chinese Cultural Values: Their dimensions and marketing implications, European Journal of Marketing, 22, pp44-57.

Yau, O.H.M. (1994), Consumer Behavior in China: Customer Satisfaction and Cultural Values, Routledge,
London.

Yau, O.H.M. and Kwong, K.K. (2002), The Conceptualization of Customer Delight: A Research Framework, Asia Pacific Management Review, 7(2), pp255-266.

Zhang, M.X. (2003), 绿仙购头行为的道家价值观灼素分析

Economic Management, 2(4), pp34-41. Zhang, M.X. (2005), 女性价值观与购头行为, Jingjiguanli Publication, Beijing. 